\title{
Correction to: Reproductive outcomes in women and men using complementary and alternative medicine treatment and not receiving artificial reproductive technology: a systematic review
}

Hannah M. Yogasundram ${ }^{1}$ - Andrew J. O. Hui ${ }^{1}$. Clifford Y. S. Sia ${ }^{1} \cdot$ Anthea C. Chui $^{1} \cdot$ William J. Waldock ${ }^{1}$. Siobhan Quenby ${ }^{2,3}$ (D) Elizabeth Brown ${ }^{4} \cdot$ Clare Oliver-Williams $^{5,6}$ (D)

Published online: 25 November 2020

(c) Springer-Verlag GmbH Germany, part of Springer Nature 2020

Correction to: Archives of Gynecology and Obstetrics https://doi.org/10.1007/s00404-020-05836-4

In the original article, the name of the fourth author is incorrect.

The correct name is Anthea C. Chui.

The original article can be found online at https://doi.org/10.1007/ s00404-020-05836-4.

\section{Clare Oliver-Williams}

cto21@cam.ac.uk

1 School of Clinical Medicine, University of Cambridge, Cambridge, UK

2 Warwick Medical School, University of Warwick, Coventry, UK

3 University Hospitals Coventry and Warwickshire, Coventry, UK

4 University College London, London, UK

5 Homerton College, University of Cambridge, Hills Road, Cambridge, UK

6 Department of Public Health and Primary Care, University of Cambridge, 2 Worts' Causeway, Cambridge CB1 8RN, UK 